\title{
Saskatchewan Silver-haired Bat Records
}

\author{
By ROBERT W. NERO, Saskatchewan Museum of Natural History
}

Published information on the distribution of mammals in Saskatchewan, as indicated by Fuller (1943), is extremely limited, particularly in the case of smaller mammals such as the bats. This situation is partly the result of a scarcity of records. The area involved is large and remote - the determination of the fauna of this province as well as its distribution a nd significance is neccessarily an immense task. The extent to which naturalists and other interested individuals can contribute to this end may be demonstrated by the present paper.

The Silver-haired Bat (Lasionyceteris noctivagans) is a mediumsized and blackish-brown bat. The hairs of the back and belly are usually tipped with silvery-white hence its name. Its wing-spread measures from 11 to 13 inches. Cameron (1951:7) considers it to be "rather rare" in Canada, although it has been stated by C. H. Merriam to be the most abundant bat in the Adirondacks of New York (Hamilton, 1943:81). In contrast with several species which breed in colonies this bat is usually thought to be solitary in habits (e.g., Burt, 1946:111). Hamilton, however, states that at times it is sociable"

often congregating in vast numbers." (1943:81). According to most authors it is found in wooded areas near water, and it is generally known as a "tree bat." It is distributed from the Atlantic to the Pacific, over most of the United States and the southern half of Canada.

Cameron states $(1951: 7)$ that the Silver-haired Bat has been recorded in Canada from Quebec west to Alberta, but Anderson also lists it for British Columbia (1946:29). This species is thought to occur throughout Alberta in the forested areas (Rand, 1948: 63). Bailey (1926:212) said that it was probably found"... over at least the forested parts of North Dakota during the breeding season and the months of greatest insect activity"-Soper (1946:135) found: ". . . no records of its occurrence on the Great Plains to the west (of Manitoba), although it doubtless occurs there as a migrant."
The general distribution of the Silver-haired Bat in Saskatchewan as shown by Palmer (1954) and Burt and Grossenheider (1952) covers all of the province except the Hudsonian life zone (northern one-quarter of the province).

Forty records of this bat in Saskatchewan during the last four decades are presented in table 1. This includes material from a published report by Banfield (1941) and from several issues of the Blue Jay. (Mrs. I. M. Priestly, through constant queries on the subject of bats in the Blue Jay from 1942 to 1946 evcked a number of valuable contributions. As a result, Rand (1942) submitted a list of Saskatchewar bats.) Records of specimens in the National Museum of Canada wer sent to the Saskatchewan Museun of Natural History by Dr. A. W Cameron. Dr. S. C. Downing for warded the data from the Roya Ontario Museum and Mr. Harve: Beck submitted a list of specimen in the collections of the Universit. of Saskatchewan. Additional record or specimens were submitted by th cthers indicated. The 18 specimen received in 1955 and 1956 resulte from public response to our news paper and radio requests for bats.

The situation in which many these bats were found (see table 1 shows that this species utilizes man made structures at least as restin places and possibly as breeding site. It might pay to look in similar place earlier in the season, in June an July, for females with young. Th large number of August and Ser tember records probably relate some aspect of the life history this species, possibly mating migration. So little is kncwn of the habits that one can only specula on the cause for this apparent in crease in appearance. Note tl nearly even sex ration (15 female 13 males) and the even month distribution of the specimens $(6 \mathrm{f}$ males - 7 males: August; 6 females 4 males: September).

The distribution of the availat records is shown on the accompan ing map. A Manitoba record at $\mathrm{T}$ Pas (ROMZP) has been includ 


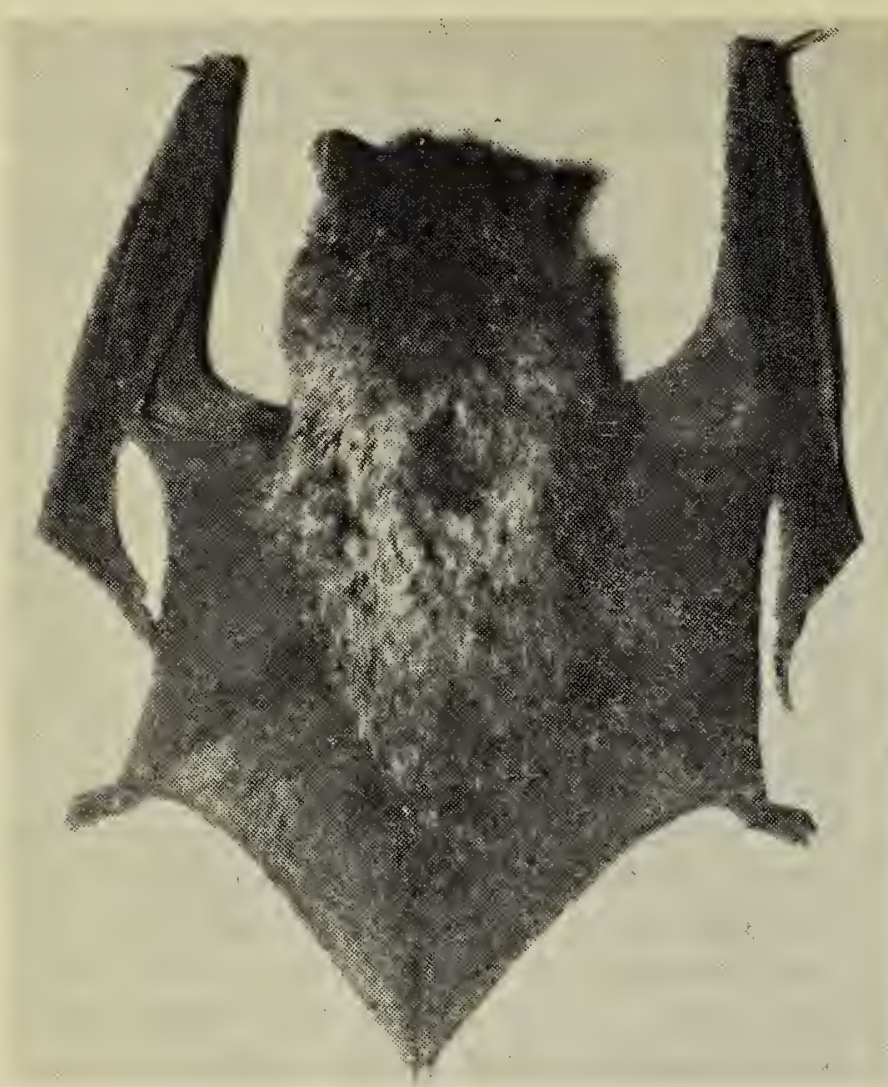

Photo by R. W. Fyfe

Female Silver-haired Bat skin.

Tregarva, Sask., Sept. 10, 1956

(This fruit, along with, of all things, cottage cheese, has long been used as a standard diet for bats in captivity.) The possibility of the closely related and equally insectivorous Red Bat feeding on fruit in the wild has been commented on by Mr. H. H. Pittman of Wauchope, Sask.: "I am not prepared to say that there is any connection, direct or indirect, between Red Bats and wild plums but where these and some of the other fruit bushes occur the bats are often found." (letter to Blue Jay, 1946, Vol. 5:5). My bats were usually fed by hand, the bats quickly seizing and rapidly devouring the small bits which were held before their sensitive nostrils. Two of the captive bats, when released in a large room, would repeatedly dip low and skim across the smooth floor, often actually touching the floor with their chin much as if they were attempting to drink. All drank greedily when presented with water while being fed.

Occasionally, when a Silver-haired Bat was disturbed as it rested on a level surface with its wings partly spread, it would, suddenly flip over onto its back, meanwhile baring its teeth and uttering its peculiar "electric spark chittering." This seemingiy aggressive or defensive behavior reminded one of a similar behavior often seen in captive owls. In a letter

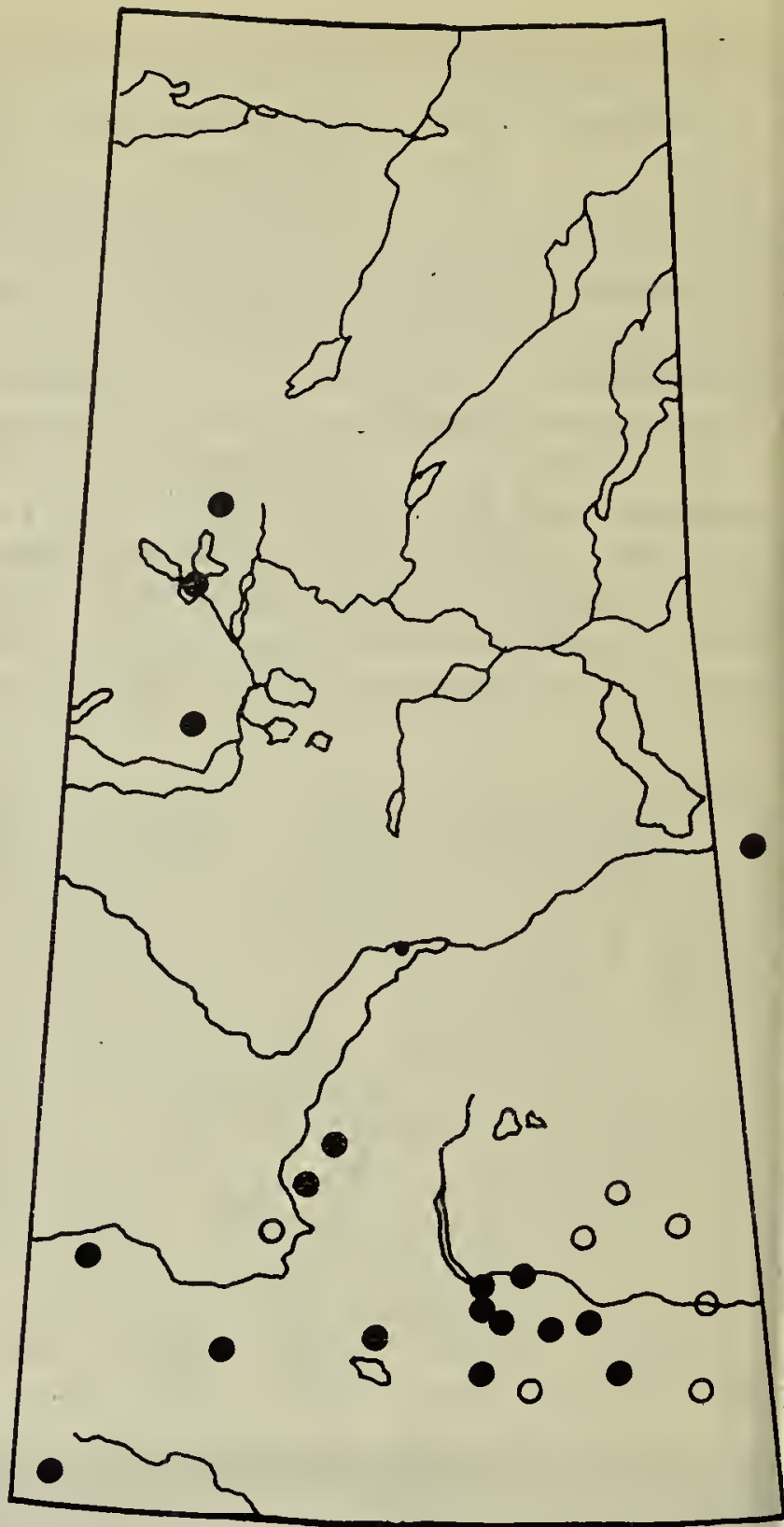

Figure 1. Silver-haired Bat Distribution: solid circles-specimens open circles-records

to the Blue Jay (1942, 1:32), $\mathrm{Mr}$. Carvell describes a bat "about $s$ inches long and grey in colo: (Hoary Bat (Lasiurus cinereus) which was lying on its back on t] ground and which ". . . when turn over with a stick quickly turn onto its back again."

When more than one bat was ke in the same container (a shoe-bo: they invariably clustered togethi one on top of the other. A furth indication of their "sociability" w obtained following the escape of fo bats in the museum library duri the last week of August, 1956. Thr males escaped a day after a iem: had escaped and disappeared (p) sumably behind books, etc.). $T$ following evening all four were fou hanging behind a curtain, the th] males clustered about the fems This behavior and the condition (Continued on Page 46) 
